\title{
FENOLOGIA DE Dalbergia cearensis DUCKE (FABACEAE) EM UM FRAGMENTO DE FLORESTA ESTACIONAL, NO SEMIÁRIDO DO NORDESTE, BRASIL ${ }^{1}$
}

\author{
Francisco Carlos Barboza Nogueira², Alípio Jose de Sousa Pacheco Filho ${ }^{3}$, Maria Izabel Gallão $^{4}$, \\ Antonio Marcos Esmeraldo Bezerra ${ }^{5}$ e Sebastião Medeiros Filho ${ }^{5}$
}

\begin{abstract}
RESUMO - Em geral, espécies arbóreas que ocorrem na vegetação de Caatinga, no semiárido do Nordeste brasileiro, têm suas fenofases (floração, frutificação e mudança foliar) condicionadas pela duração e intensidade da seca sazonal. Este estudo registrou a fenologia da queda foliar, incisão, floração e frutificação em 32 indivíduos de Dalbergia cearensis. Os indivíduos foram amostrados a cada 15 dias em 2009-10 e 201011, na Unidade de Conservação de Uso Sustentável "Fazenda Não me Deixes”, situada em Quixadá, Ceará, Semiárido brasileiro. A frequência de ocorrência das fenofases foi relacionada com os elementos do clima (precipitação pluviométrica média mensal, temperatura média mensal, insolação média mensal e disponibilidade hídrica no solo). A fenologia vegetativa, queda e brotamento de novas folhas, acompanhou a sazonalidade da precipitação pluviométrica durante as estações seca e chuvosa. A floração e frutificação ocorreram no início das chuvas, e os diásporos de D. cearensis são dispersos o ano inteiro, após se desprenderem lentamente das panículas axilares compactas.
\end{abstract}

Palavras-chave: Deciduidade; Sazonalidade; Fenofases.

\section{PHENOLOGY OF Dalbergia cearensis DUCKE (FABACEAE) IN A SHERED OF SEASONAL FOREST IN THE NORTHEAST SEMIARID, BRAZIL}

\begin{abstract}
In general, tree species that occur in the Caatinga vegetation in the Brazilian semiarid of the northeastern region, have their phenophases (flowering, fruiting and foliage change) conditioned by the duration and intensity of seasonal drought. This study records the phenology of leaf-fall, leaf incision, flowering and fruit production of 32 Dalbergia cearensis Ducke individuals. Samples were collected every 15 days from 2009 to 2011 at the Unidade de Conservação de Uso Sustentável Fazenda Não me Deixes, a conservation area in the Brazilian semiarid. The frequency of occurrence of the phenophases was related to the elements of climate (average monthly rainfall, monthly average temperature, monthly average insolation and soil water availability). The vegetative phenology, leaffall and sprouting of new leaves, followed the seasonality of rainfall during the dry and rainy seasons. The flowering and fruiting occurred at the beginning of the rains, and the diaspores of $\boldsymbol{D}$. cearensis were scattered throughout the year after they broke off slowly from the compact axillary panicles.
\end{abstract}

Keywords: Deciduous; Seasonality; Phenophases.

\footnotetext{
${ }^{1}$ Recebido em 10.05.2012 aceito para publicação em 06.08.2013.

${ }^{2}$ Instituto Brasileiro do Meio Ambiente e dos Recursos Naturais Renováveis, IBAMA, Brasil. E-mail: <fcbarbozanogueira@hotmail.com>.

${ }^{3}$ Programa de Pós-Graduação em Ecologia e Recursos Naturais, Universidade Federal do Ceará, Departamento de Biologia, Fortaleza, CE, Brasil. E-mail: <alipiopachecofilho@hotmail.com>.

${ }^{4}$ Universidade Federal do Ceará, Departamento de Biologia, Fortaleza, CE, Brasil. E-mail: <izagalao@gmail.com>.

${ }^{5}$ Universidade Federal do Ceará, Departamento de Fitotecnia, Fortaleza, CE, Brasil. E-mail:<esmeraldo@ufc.br>e filho@ufc.br>.
} 


\section{INTRODUÇÃO}

Nas regiões onde os períodos secos e úmidos se alternam, o desencadeamento dos eventos fenológicos é afetado pela periodicidade das chuvas e disponibilidade de água no solo (PAVÓN; BRIONES, 2001; JOLLY; RUNNING, 2004; SINGH; KUSHWAHA, 2005). Nessas regiões, os estudos que procuram explicar os padrões fenológicos das espécies vegetais são particularmente importantes, sobretudo para entender como as florestas secas funcionam, pois nelas as secas sazonais são muito mais pronunciadas do que as que ocorrem em florestas não sazonais (JUSTINIANO; FREDERICKSEN, 2000).

Em geral, a estrutura e funcionamento de florestas secas são influenciados pela disponibilidade hídrica sazonal: a incisão foliar ocorre um pouco antes e no início da estação chuvosa; a floração e frutificação ocorrem durante e no final da estação seca, ao passo que o aumento da abscisão foliar se correlaciona positivamente com o início da estação seca (REICH; BORCHERT, 1982; 1984; JUSTINIANO; FREDERICKSEN, 2000). No entanto, esse não é o padrão predominante em regiões marcadas pela estacionalidade climática, especialmente nos locais onde a disponibilidade hídrica é maior, tal qual em margens de riachos e rios. Há espécies lenhosas, em regiões semiáridas, que a abscisão foliar ocorre ao final da estação chuvosa, enquanto outras espécies mantêm suas folhas durante a estação seca, resultando em padrões arbóreos diferenciados no tempo e espaço (MACHADO et al., 1997; BORCHERT et al., 2002).

Esses diferentes padrões fenológicos presentes em florestas sazonais se manifestam por meio das estratégias adaptativas adotadas pelas plantas com relação ao consumo e controle da perda de água (HOLBROOK et al., 1995). Geralmente, nessas regiões as árvores exibem crescimento periódico e sazonal imposto pela sazonalidade do clima. A curta estação chuvosa representa, para a maioria das espécies vegetais, a retomada do crescimento, pois a água nesse período é abundante e os nutrientes do solo podem ser prontamente absorvidos pelas raízes (GRIZ; MACHADO, 2001). No entanto, a maioria das espécies arbóreas perde folhas na seca sazonal, para evitar a transpiração, e rebrotam logo nas primeiras chuvas (REICH; BORCHERT, 1984; BULLOCK; SOLIS-MAGALLANES, 1990). Nessas regiões, os padrões de floração e frutificação são complexos, com a floração ocorrendo no início da estação das chuvas, seguida pela frutificação (MACHADO et al., 1997). Quanto à estratégia reprodutiva, predomina a produção de frutos secos, anemocóricos, com sementes pequenas, ortodoxas, com diásporos dispersos durante a seca (JUSTINIANO; FREDERICKSEN, 2000; GRIZ; MACHADO, 2001).

A duração e intensidade da seca, especialmente em florestas decíduas de regiões tropicais, determinam a periodicidade das fenofases (floração, frutificação e mudança foliar), pois em baixas latitudes há pouca variação anual da temperatura e do fotoperíodo (REICH; BORCHERT, 1982; BORCHERT, 1996; BORCHERT et al., 2005). Aliadas às características intrínsecas das plantas, as variações climáticas também exercem influência sobre a periodicidade pela qual os eventos fenológicos se manifestam (FOURNIER, 1974). Por isso, compreender o comportamento sazonal das fenofases servirá para entender a regeneração, a reprodução e a organização temporal dos recursos das populações vegetais nessas regiões marcadas pela sazonalidade hídrica do clima (SILVERTOWN, 1980; KELLY; SORK, 2002; ROCHA et al., 2006).

O semiárido do Nordeste brasileiro encontra-se inserido na posição subequatorial (baixa latitude tropical), apresenta média de temperaturas mensais entre 23$27^{\circ} \mathrm{C}$, com menos de $5{ }^{\circ} \mathrm{C}$ de variação mensal e $5-10^{\circ} \mathrm{C}$ de variação diária (SAMPAIO, 1995), e possui padrão de distribuição de chuvas bastante irregular no tempo e no espaço (NIMER, 1989). Essas características ambientais são semelhantes àquelas das demais regiões localizadas em baixas latitudes expostas à temperatura e fotoperíodos constantes (REICH; BORCHERT, 1982; BORCHERT, 1996; BORCHERT et al., 2005). Além disso, é uma região que apresenta déficit hídrico durante grande parte do ano e, pelo fato de a intensidade do déficit variar muito, a fisionomia da vegetação e a flora locais podem variar (SAMPAIO, 1995). Nesse contexto, em que a restrição hídrica sazonal representa o fator ambiental mais marcante dessa região, supõe-se que a fenologia da espécie Dalbergia cearensis Ducke, endêmica, possa expressar os efeitos da seca sazonal na oferta de recursos local (flores, frutos e folhas), através da sazonalidade de seus padrões fenológicos vegetativos e reprodutivos, em anos consecutivos com disponibilidade hídrica diferente, abaixo e acima da média histórica.

Espera-se que a fenologia vegetativa e reprodutiva da espécie focal acompanhe a sazonalidade da precipitação pluviométrica durante a estação seca e 
chuvosa. Semelhante ao que foi descrito por Lorenzi (2009), espera-se, também, que a queda foliar da espécie focal ocorra no início da estação seca e o brotamento de novas folhas apareça com as primeiras chuvas. Quanto à estratégia reprodutiva, presume-se que a floração e frutificação aconteçam no período de chuvas e a dispersão dos frutos no período seco (LORENZI, 2009). Para testar essas previsões, o padrão fenológico da espécie Dalbergia cearensis foi correlacionado com a precipitação pluviométrica, insolação, temperatura e disponibilidade hídrica no solo.

\section{MATERIAL E MÉTODOS}

\subsection{Localização e caracterização ambiental da área de estudo}

O estudo foi realizado em um fragmento de 300 ha da floresta xerófila espinhosa na Unidade de Conservação de Uso Sustentável Fazenda Não me Deixes (449’34" S, 3858'9" W e 210 m de altitude), Município de Quixadá, Estado do Ceará, Nordeste do Brasil. O clima é Aw' de Köppen (1948). Trata-se da região pertencente ao grupo de clima tropical chuvoso, com temperatura média do mês mais frio superior ou igual a $18^{\circ} \mathrm{C}$ e precipitação do mês mais seco menor que $30 \mathrm{~mm}$, em que a época mais seca ocorre no inverno e o máximo de chuvas no outono (EMBRAPA, 2004). A temperatura anual média é de $27,2^{\circ} \mathrm{C}$, a média das máximas $32,4^{\circ} \mathrm{C}$ e a média das mínimas $22,3{ }^{\circ} \mathrm{C}$; na estação chuvosa (janeiro-maio), chove mais de $75 \mathrm{~mm}$ mensais, concentrando $85 \%$ do total anual; e na estação seca (junho a dezembro) chove menos que $51 \mathrm{~mm}$ mensais. A insolação anual é de $3.143,8$ h, com a menor registrada em março (216,5 h/mês) e a maior, em outubro (368,1 h/mês) (EMBRAPA, 2004).

O índice pluviométrico $1.189,80 \mathrm{~mm}$ foi elevado em 2009, mas em 2010 foi baixo (501,9 mm), comparado aos $863,4 \mathrm{~mm}$ da média histórica registrada entre 1980 e 2003 (EMBRAPA, 2004). A temperatura média anual em 2009 foi de $25,2{ }^{\circ} \mathrm{C}$ nos meses mais frios (junho e julho), a $28,8^{\circ} \mathrm{C}$ em dezembro, mês mais quente. Em 2010 , a temperatura média anual variou de $27,2^{\circ} \mathrm{C} \mathrm{em}$ junho (mês mais frio) a $34,8^{\circ} \mathrm{C}$ em novembro (mês mais quente). As médias mensais de precipitação e temperatura aqui registradas foram cedidas pela Estação Lavoura Seca, localizada no Município de Quixadá, pertencente à Universidade Federal do Ceará e vinculada ao Instituto Nacional de Meteorologia.
Na estimativa da disponibilidade de água no solo para a população de $D$. cearensis, utilizou-se o método do balanço hídrico. Esse método consiste em quantificar a água armazenada no interior do solo, mediante o saldo do que entrou e do que saiu nas diferentes épocas doano(D'ANGIOLELLA; VASCONCELLOS, 2003; 2004).

\subsection{A espécie estudada}

Dalbergia cearensis Ducke (Fabaceae: Faboideae) é uma espécie decídua endêmica da floresta xerófila espinhosa do Nordeste do Brasil (CARVALHO, 1997) e pode atingir 5-8 $\mathrm{m}$ de altura, tendo madeira com 1,01 $\mathrm{g} / \mathrm{cm}^{3}$ de densidade específica (LORENZI, 2009). Sua madeira é muito utilizada para a confecção de móveis de luxo e instrumentos musicais (RIZZINI, 1978; LORENZI, 2009). Suas plantas não têm estruturas armazenadoras de água no caule ou na raiz, perdem as folhas no início da estação seca, permanecem decíduas por quatro a seis meses, emitem novas folhas e florescem no início da estação chuvosa e seus frutos amadurecem no início da estação seca (LORENZI, 2009). Suas sementes apresentam alto percentual de germinação (70\%), que tem início a partir do terceiro dia após a semeadura e produzem plântulas do tipo fanero-epígeoarmazenadoras (NOGUEIRA et al., 2010).

\subsection{Coleta dos dados fenológicos}

Escolheram-se 32 indivíduos adultos de Dalbergia cearensis distribuídos em aproximadamente 8,0 ha na área da RPPN. Esse número foi o triplo do proposto por Fournier e Charpantier (1975) para esse tipo de amostragem. Os critérios de escolha dos indivíduos foram ausência aparente de doenças e infestações de parasitas, diâmetro à altura do peito e" $10 \mathrm{~cm}$ e copa totalmente visível. Cada indivíduo recebeu uma placa de identificação de plástico numerada. As coletas e observações fenológicas foram realizadas quinzenalmente entre maio de 2009 e abril de 2011.

Registraram-se o início e término da floração, frutificação, abscisão foliar e brotamento. Para estimar a intensidade das fenofases em cada indivíduo, utilizaram-se o método proposto por Fournier (1974). O método consiste em estabelecer escalas intervalares semiquantitativas de cinco categorias ( 0 a 4 ), com intervalos de $25 \%$ entre cada categoria: zero = ausência de fenofase, $1=$ presença da fenofase, com magnitude atingindo entre $1 \%$ e $25 \%, 2=$ presença de fenofase com magnitude atingindo entre $26 \%$ e $50 \%, 3=$ presença 
de fenofase com magnitude atingindo entre $51 \%$ e $75 \%$ e $4=$ presença de fenofase com magnitude atingindo entre $76 \%$ e $100 \%$. Na definição da duração das fenofases, a floração de no mínimo um indivíduo correspondeu apenas ao período com presença de flores, sem distinção entre botão floral e flor aberta; a duração da frutificação foi caracterizada como o período em que as árvores apresentaram frutos verdes imaturos, maduros de cor amarela a cinza-clara e escura e prontos para dispersão; a duração do brotamento foi registrada a partir do aparecimento de novas folhas; e abscisão, quando as folhas mudaram de cor e se desprendiam dos galhos com facilidade. A intensidade determinada por meio do índice Fournier (1974) permite que os picos fenológicos sejam mais evidentes.

Para avaliar a porcentagem de indivíduos em cada fenofase ou índice de atividade, seguiram-se Bencke e Morellato (2002). Esse método permite avaliar a sincronia dos eventos fenológicos entre os indivíduos da população. Evento fenológico assincrônico foi aquele caracterizado por meio da ocorrência de menos de $20 \%$ de indivíduos em determinada fenofase; e baixa sincronia, quando 20 a $60 \%$ de indivíduos se apresentavam em certa fenofase e alta sincronia acima de $60 \%$ dos indivíduos.

\subsection{Testes de distribuição e correlação entre variáveis ambientais e fenologia}

Antes de investigar a influência dos fatores climáticos sobre a fenologia dos indivíduos, aplicouse o teste não paramétrico de Shapiro e Wilks (ZAR, 1996) para verificar a hipótese de normalidade. A porcentagem de indivíduos em cada fenofase foi relacionada à precipitação pluviométrica média mensal, insolação média mensal, temperatura média mensal e disponibilidade hídrica no solo, por meio da correlação de Spearman ( $\left.\mathrm{r}_{\mathrm{s}}\right)(\mathrm{ZAR}, 1996)$. Os testes estatísticos foram processados no software SPSS 14.0 for Windows (SPSS, 2007).

\subsection{Distribuição de frequências}

Utilizou-se estatística circular para analisar como as distribuições de frequências dos 32 indivíduos de $D$. cearensis ocorriam em cada fenofase e período de observação. Primeiramente, os meses foram convertidos em ângulos, de acordo com o número de coleta dos dados. Por exemplo, como no período entre maio de 2009 e abril de 2010 foram realizadas
23 coletas, e dividiu-se o ângulo circular de $360^{\circ}$ por 23 , gerando ângulos de $15,65^{\circ}$. Desse modo, calculou-se a frequência de ocorrência dos indivíduos em cada fenofase em cada ângulo. As seguintes variáveis foram estimadas para cada fenofase e em cada ano: ângulo médio ( $\mu$ - ângulo médio), a dispersão angular (variância angular), limites de confiança da distribuição de frequência e o vetor ( $\mathrm{r}$ - uma medida de concentração dos dados ao redor do ângulo médio). Como as análises foram realizadas em ângulos, esses valores foram convertidos em dia, de modo que cada dia equivale a aproximadamente $0,99^{\circ}$ (primeiro de maio).

A análise de estatística circular possibilita testar o efeito da estacionalidade sobre a fenologia. Para tal, foram analisados o $\mu$ e o Z. O ângulo médio $(\mu)$ é o período do ano em torno da qual determinada fenofase ocorreu na maioria dos indivíduos. O teste de Rayleigh (Z) determina o nível de significância do ângulo médio. A hipótese nula é a de que os dados são distribuídos uniformemente ou casualizados ao longo do ano (ou do círculo), ou seja, não há efeito da estacionalidade sobre a fenofase. A hipótese alternativa é a de que os dados não são distribuídos aleatoriamente ao longo do ano, isto é, há um ângulo médio significativo e, portanto, há efeito da estacionalidade. Caso a hipótese alternativa seja aceita, a intensidade da concentração (r) ao redor do ângulo pode ser considerada como medida da magnitude do efeito da estacionalidade sobre a fenologia. Dessa forma, r varia de 0 (a atividade fenológica é distribuída uniformemente ao longo do ano) a 1 (a atividade fenológica é concentrada em um período do ano).

\section{RESULTADOS}

O comportamento dos indivíduos em cada fenofase foi agrupado no tempo, representado pelos períodos 2009-10 e 2010-11, nas variáveis médias mensais de precipitação pluviométrica, temperatura média mensal, insolação média mensal e disponibilidade hídrica no solo. Essas variáveis climáticas influenciaram as fenofases abscisão foliar (queda), incisão foliar (brotamento), floração e frutificação, conforme pode ser observado nas Figuras $1 \mathrm{AB}$ a $4 \mathrm{AB}$.

\subsection{Abscisão foliar}

Em 2009-10, essa fenofase correlacionou-se negativamente com a precipitação média mensal $\left(r_{s}=-0,699 ; p<0,001\right)$ e positivamente com a temperatura 
média mensal $\left(\mathrm{r}_{\mathrm{s}}=0,451 ; \mathrm{p}<0,05\right)$. No entanto, a insolação média mensal $\left(r_{s}=-0,381 ; p>0,05\right)$ e disponibilidade hídrica $\left(\mathrm{r}_{\mathrm{s}}=-0,191 ; \mathrm{p}>0,05\right)$ não se correlacionaram com a queda foliar. Em 2010-11, a precipitação média mensal $\left(r_{s}=-0,765 ; p<0,001\right)$ e a disponibilidade hídrica no solo $\left(r_{s}=-0,653 ; p<0,05\right)$ correlacionaram-se negativamente com a queda foliar, porém a queda foliar foi positivamente correlacionada com a temperatura média mensal $\left(\mathrm{r}_{\mathrm{s}}=0,871 ; \mathrm{p}<0,001\right)$ e a insolação média mensal $\left(\mathrm{r}_{\mathrm{s}}=0,831 ; \mathrm{p}<0,001\right)$.
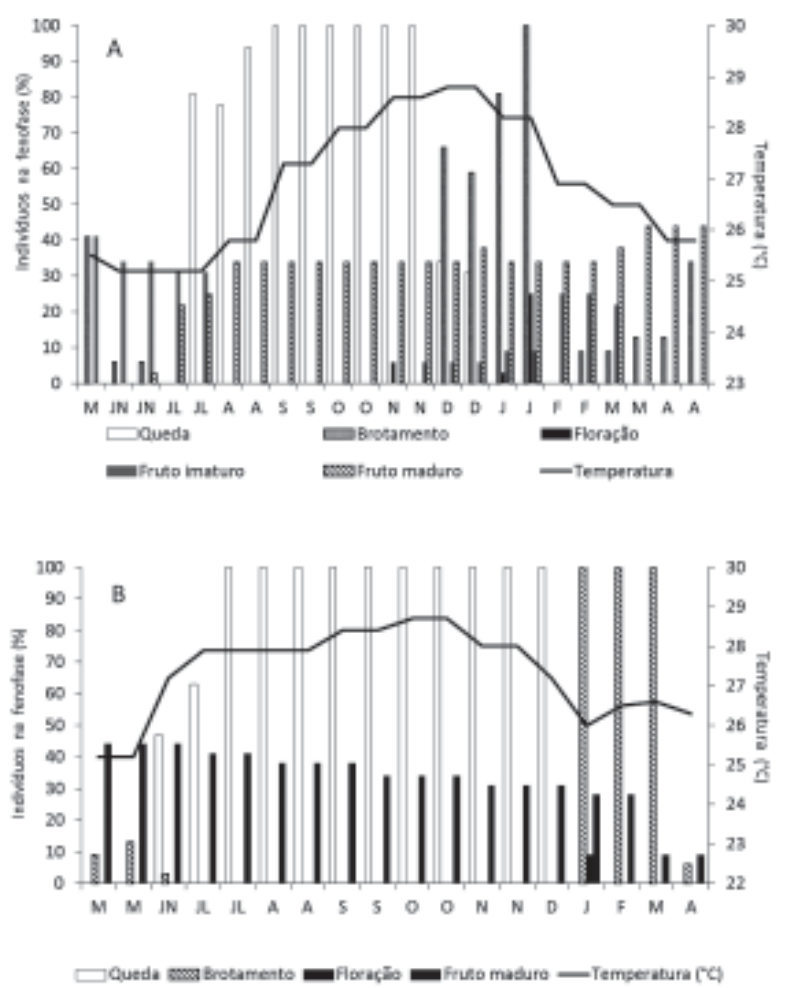

Figura 1 - Influência da precipitação média mensal sobre os indivíduos de Dalbergia cearensis Ducke nas fenofases queda de folhas, brotamento, floração e frutificação localizados na Unidade de Conservação de Uso Sustentável "Fazenda Não me Deixes", Quixadá, Ceará. A: período de maio de 2009 a abril de 2010; e B: período de maio de 2010 a abril de 2011.

Figure 1 - Influence of the average monthly rainfall over individuals of Dalbergia cearensis Ducke in phenophases of leaf abscission, sprouting, flowering and fruit maturation at Unidade de Conservação de Uso Sustentável Fazenda Não me Deixes (Quixadá, Ceará). A: From May 2009 to April 2010 and B: from May 2010 to April 2011.
A população apresentou alta sincronia para abscisão foliar a partir da segunda quinzena de julho até dezembro; nos demais meses houve baixa sincronia. O comprimento do vetor médio nos dois períodos de estudo foi de $0,58$ para 2009-10 ( $<<0,001)$ e 0,64 para 2010-11 ( $<<0,001)$, como mostrado na Tabela 1.

\subsection{Incisão foliar}

Em 2009-10 houve correlação positiva entre essa fenofase e a precipitação média mensal $\left(r_{s}=0,622 ; p<0,05\right)$
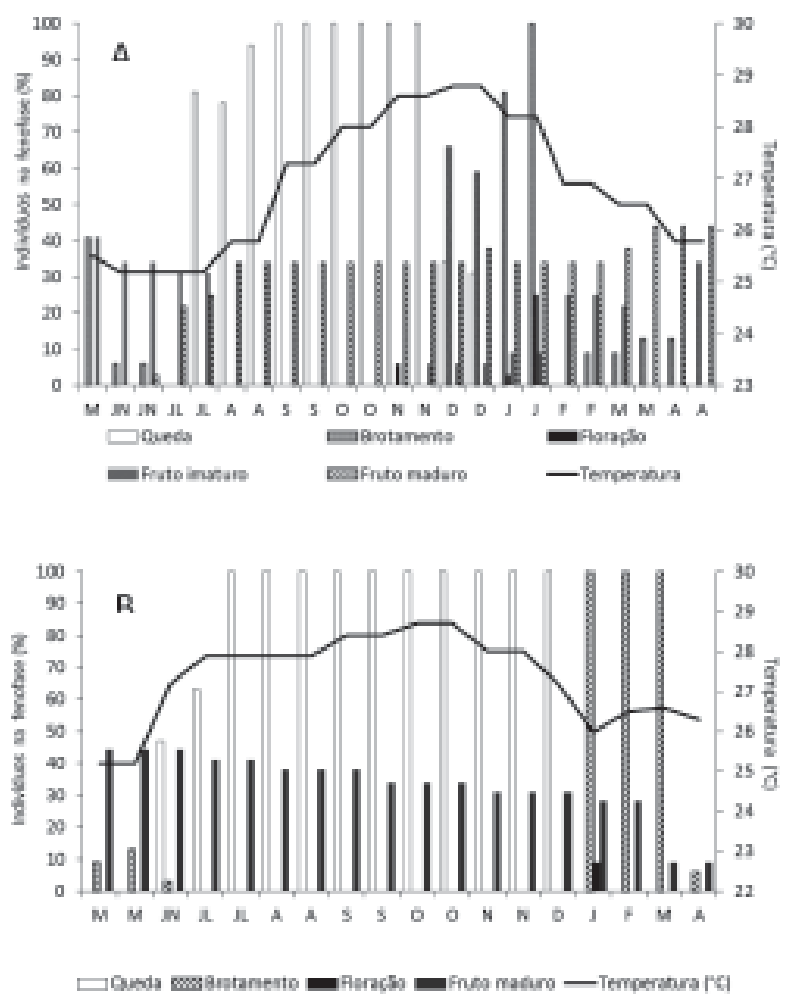

Figure 2 - Influence of the mean monthly temperature over individuals of Dalbergia cearensis Ducke in phenophases of leaf abscission, sprouting, flowering and fruit maturation at Unidade de Conservação de Uso Sustentável Fazenda Não me Deixes (Quixadá, Ceará). A: From May 2009 to April 2010 and B: from May 2010 to April 2011.

Figura 2 - Influence of the Average monthly temperature over individuals of Dalbergia cearensis Ducke in phenophases of leaf abscission, sprouting, flowering and fruit maturation at Unidade de Conservação de Uso Sustentável Fazenda Não me Deixes (Quixadá, Ceará). A: From May 2009 to April 2010 and B: from May 2010 to April 2011.

Revista Árvore, Viçosa-MG, v.37, n.4, p.657-667, 2013 
e insolação média mensal $\left(\mathrm{r}_{\mathrm{s}}=0,502 ; \mathrm{p}<0,05\right)$. No entanto, as demais variáveis climáticas não se correlacionaram: temperatura média mensal $\left(\mathrm{r}_{\mathrm{s}}=0,124 ; \mathrm{p}>0,05\right) \mathrm{e}$ disponibilidade hídrica no solo $\left(\mathrm{r}_{\mathrm{s}}=-0,152 ; \mathrm{p}>0,05\right)$. No período 2010-11, o brotamento foliar correlacionou-se positivamente com a precipitação média mensal $\left(r_{\mathrm{s}}=0,821 ; \mathrm{p}<0,001\right)$ e disponibilidade hídrica no solo $\left(r_{s}=0,722 ; p=0,001\right)$ e negativamente com a temperatura média mensal $\left(r_{s}=-0,826 ; p<0,001\right)$ e insolação média mensal $\left(r_{s}=-0,786 ; p<0,001\right)$. A emissão de brotos foliares
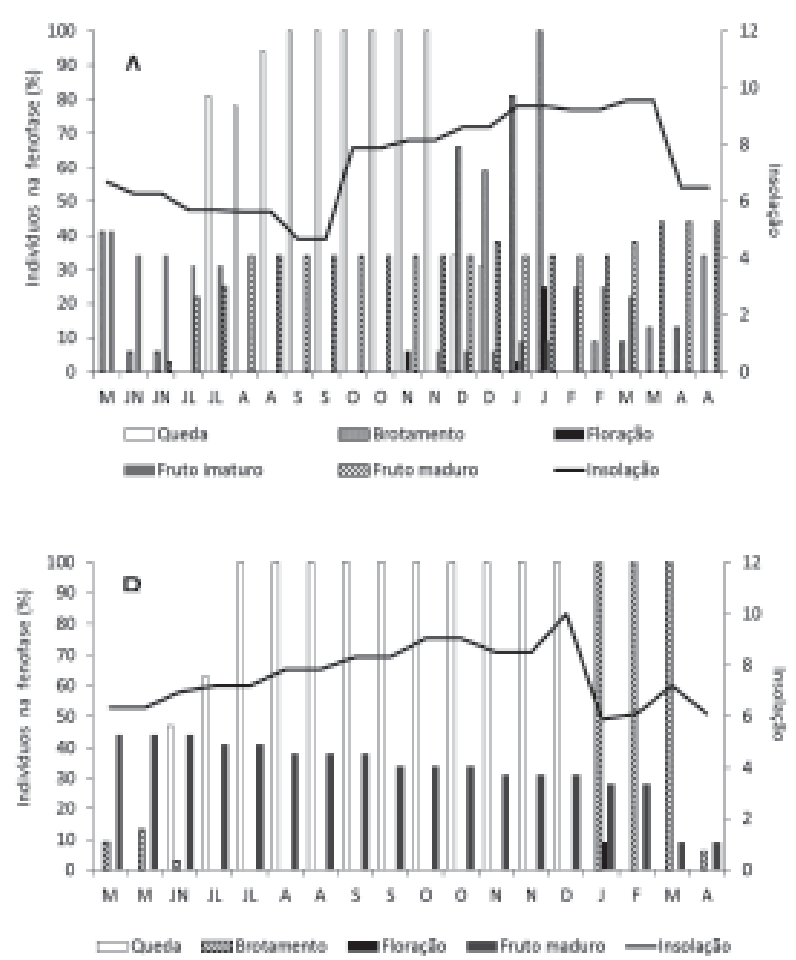

Figure 3 - Influence of the monthly average solar radiation over individuals of Dalbergia cearensis Ducke in phenophases of leaf abscission, sprouting, flowering and fruit maturation at Unidade de Conservação de Uso Sustentável Fazenda Não me Deixes (Quixadá, Ceará). A: From May 2009 to April 2010 and $\mathbf{B}$ : from May 2010 to April 2011.

Figura 3 - Influence of the monthly average insolation over individuals of Dalbergia cearensis Ducke in phenophases of leaf abscission, sprouting, flowering and fruit maturation at Unidade de Conservação de Uso Sustentável Fazenda Não me Deixes (Quixadá, Ceará). A: From May 2009 to April 2010; and B: from May 2010 to April 2011.

Revista Árvore, Viçosa-MG, v.37, n.4, p.657-667, 2013 foi altamente sincrônica na população nos meses de janeiro, fevereiro e março. O comprimento do vetor médio foi 0,72 para $2009-10(p<0,001)$ e 0,86 para 2010 $11(\mathrm{p}<0,001)$, como visto na Tabela 1 .

\subsection{Floração}

A floração em 2009-10 correlacionou-se positivamente com a temperatura média mensal $\left(r_{s}=0,462 ; p<0,05\right)$. Porém não houve correlação com precipitação média mensal $\left(r_{s}=0,049 ; p>0,05\right)$, insolação média mensal
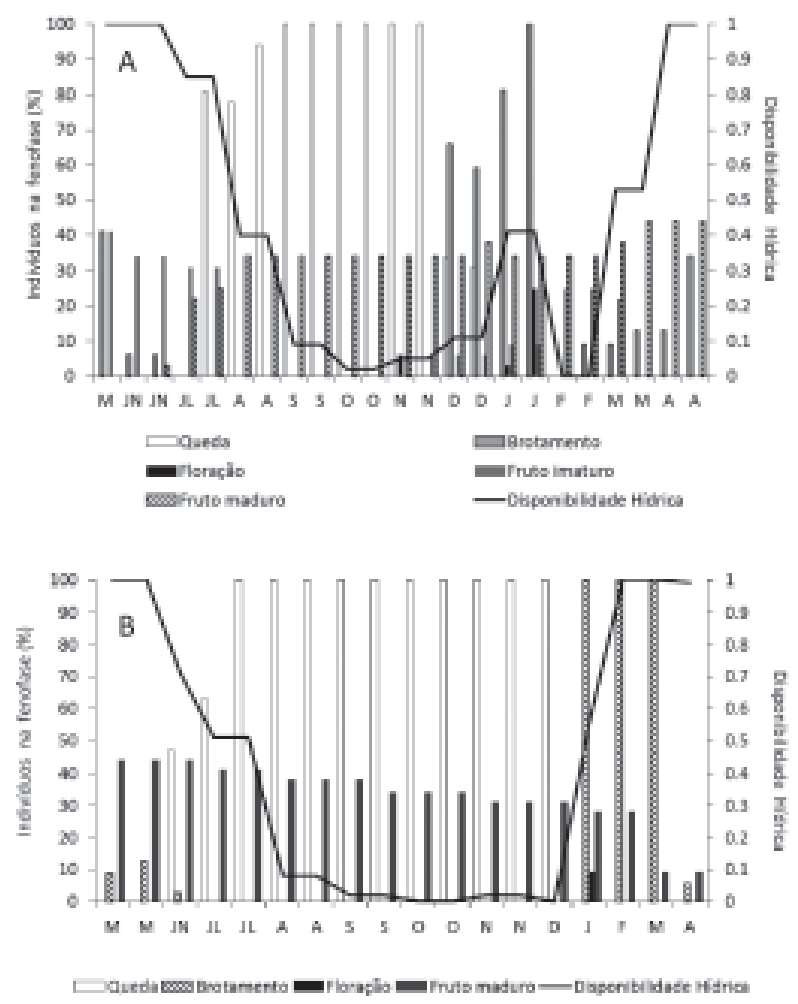

Figure 4-Influence of the soil water availability over individuals of Dalbergia cearensis Ducke in phenophases of leaf abscission, sprouting, flowering and fruit maturation at Unidade de Conservação de Uso Sustentável Fazenda Não me Deixes (Quixadá, Ceará). A: From May 2009 to April 2010 and B: from May 2010 to April 2011.

Figura 4 - Influence of the soil water availability over individuals of Dalbergia cearensis Ducke in phenophases of leaf abscission, sprouting, flowering and fruit maturation at Unidade de Conservação de Uso Sustentável Fazenda Não me Deixes (Quixadá, Ceará). A: From May 2009 to April 2010; and B: from May 2010 to April 2011. 
Table 1 - Circular statistics of phenophases in Dalbergia cearensis for the period May 2009 to April 2011, in the RPPN Fazenda Não me Deixes (Quixadá, Ceará). ì - average angle. r - a measure of data concentration around the average angle. DPC - circular standard deviation. Rayleigh Z - Rayleigh test. p - significance level of the average angle (0.05).

Tabela 1 - Circular statistics of phenophases in Dalbergia cearensis from May 2009 to April 2011, in the RPPN Fazenda Não me Deixes (Quixadá, Ceará). $\mu$ - average angle. $r$ - a measure of data concentration around the average angle. DPC - circular standard deviation. Rayleigh $Z$ - Rayleigh test. $p$-significance level of the average angle (0.05)

\begin{tabular}{|c|c|c|c|c|c|c|c|c|}
\hline \multirow{2}{*}{ Estatística circular } & \multicolumn{2}{|c|}{ Queda foliar } & \multicolumn{2}{|c|}{ Incisão foliar } & \multicolumn{2}{|c|}{ Floração } & \multicolumn{2}{|c|}{ Frutificação } \\
\hline & $2009-10$ & $2010-11$ & $2009-10$ & $2010-11$ & $2009-10$ & $2010-11$ & $2009-10$ & 2010-11 \\
\hline$\mu^{1}$ & $194,34^{\circ}$ & $169,78^{\circ}$ & $291,05^{\circ}$ & $292,92^{\circ}$ & $271,92^{\circ}$ & $285^{\circ}$ & $315^{\circ}$ & $117,02^{\circ}$ \\
\hline$r^{2}$ & 0,58 & 0,64 & 0,72 & 0,86 & 1 & 0,97 & 0,07 & 0,28 \\
\hline $\mathrm{DPC}^{3}$ & $63,85^{\circ}$ & $53,81^{\circ}$ & $46,22^{\circ}$ & $31,27^{\circ}$ & - & $12,34^{\circ}$ & $131,95^{\circ}$ & $91,07^{\circ}$ \\
\hline Rayleigh Z & 34,36 & 75,33 & 53,20 & 50,48 & 15 & 5,72 & 0,71 & 8,47 \\
\hline $\mathrm{p}^{4}$ & $>0,001$ & $>0,001$ & $>0,001$ & $>0,001$ & $>0,001$ & $>0,001$ & 0,489 & $>0,001$ \\
\hline
\end{tabular}

$\left(\mathrm{r}_{\mathrm{s}}=0,406 ; \mathrm{p}>0,05\right)$ e disponibilidade hídrica no solo $\left(r_{s}=-0,342 ; p>0,05\right)$. Em 2010-11, a floração não se correlacionou com a variável climática alguma. A floração manifestou-se assincrônica na população. O comprimento do vetor médio em ambos os períodos foi 1,0 para 200910 ( $p<0,001)$ e 0,97 para 2010-11( $<<0,001)$, como mostrado na Tabela 1.

\subsection{Frutificação}

Apenas a disponibilidade hídrica no solo correlacionou-se negativamente com frutos maduros $\left(r_{s}=-0,429 ; p<0,05\right)$ e $\left(r_{s}=-0,493 ; p<0,05\right)$, respectivamente no primeiro e no segundo ano. As demais variáveis não se correlacionaram com frutos maduros. $\mathrm{O}$ evento frutificação foi pouco sincrônico ou assincrônico. $\mathrm{O}$ comprimento do vetor médio no primeiro ano foi 0,07 ( $p>0,05)$ e no segundo, 0,28 ( $p<0,001)$, isto é, não houve efeito da estacionalidade na ocorrência de frutificação (Tabela 1).

\section{DISCUSSÃO}

O padrão bianual de abscisão foliar manifestado por $D$. cearensis foi característico de espécies decíduas. A abscisão foliar exibiu alta sincronia nos meses mais secos do ano (julho a dezembro) e em ambos os períodos estudados correlacionou-se positivamente com a ausência de precipitação e escassez de água no solo. O primeiro período do estudo teve chuvas mais prolongadas do que no segundo período (2009, com $1.189,80 \mathrm{~mm}$; 2010, com 501,9 mm). Esse fato pode ter contribuído para que a disponibilidade hídrica no solo não tenha se correlacionado com queda foliar. No entanto, no segundo período a influência do estresse hídrico, representado pela correlação negativa com a disponibilidade hídrica e com a precipitação nos dois períodos em análise, sugere a possibilidade de que a precipitação e a disponibilidade hídrica no solo sejam os desencadeadores da queda foliar.

Em condições de sazonalidade de precipitação definida, Bullock e Solís-Magallanes (1990) encontraram um padrão semelhante de queda de folhas influenciado pelas chuvas em floresta decídua no México. Resultado semelhante tambémm foi observado na Bolívia, em floresta tropical seca, sendo os meses mais secos do ano relacionados com o pico de queda das folhas da vegetação (JUSTINIANO; FREDERICKSEN, 2000). Outra espécie, Dalbergia retusa, mostrou queda de folhas em solos rasos sujeitos à seca na floresta semidecídua de Guanacaste, Costa Rica. Nesse ambiente, a espécie em questão apresentou padrão breve decíduo, pois formou novas folhas durante a estação seca (BORCHERT et al., 2002).

Se por um lado a abscisão foliar proporciona economia hídrica para as plantas no período seco, por outro acarreta a perda de nutrientes para a planta. Essa demanda por água e perda de nutrientes é acentuada em solos com elevada fertilidade, nos quais as plantas podem facilmente obter os nutrientes que foram perdidos devido à abscisão foliar (JARAMILLO; SANFORD, 1995). Essa influência da disponibilidade de nutrientes no solo não se restringe apenas à fenologia vegetativa da queda foliar, pois todo o ciclo reprodutivo das plantas 
pode ser afetado pela quantidade de nutrientes disponíveis no solo (ZAGT, 1997).

A intensidade de abscisão foliar na vegetação de Caatinga pode variar entre as espécies que mantêm suas folhas durante o período seco e as que permanecem sem folhas durante seis meses do ano (MACHADO et al., 1997). Essa amplitude de deciduidade é um padrão já detectado em outras florestas tropicais que crescem sob clima estacional (BULLOCK; SOLÍS-MAGALLANES, 1990; BORCHERT et al., 2002; SINGH; KUSHWAHA, 2005). Em geral, a abscisão foliar em espécies florestais depende da intensidade da seca sazonal e do potencial de reidratação e controle da perda d'água (REICH; BORCHERT, 1984).

Há espécies da vegetação de Caatinga que lançam novas folhas antes da estação chuvosa, porque foram influenciadas por meio da ocorrência de chuvas esporádicas (MACHADO et al., 1997). Observou-se que Dalbergia cearensis emitiu brotos foliares quando as chuvas se anteciparam e caíram nos meses secos (novembro e dezembro). Esse tipo de padrão foi observado em outras espécies de florestas secas sob estacionalidade climática (BULLOCK; SOLÍSMAGALLANES, 1990; YADAV; YADAV, 2008). Contudo, há na região de Caatinga plantas que também têm seu ritmo de duração dos eventos fenológicos governados pela densidade de sua madeira e pela capacidade de armazenamento de água no caule. Nesse caso, espécies com baixa densidade de madeira e que podem armazenar água em seus caules têm o fotoperíodo como principal fator responsável pelo início do brotamento de folhas. Essas espécies iniciam o brotamento ao final da estação seca (LIMA; RODAL, 2010).

A produção de novas folhas no final da estação seca e no início das chuvas foi também registrada em diversos estudos realizados em florestas tropicais secas (SINGH; KUSHWAHA, 2005; ELLIOT et al., 2006; YADAV; YADAV, 2008). A maioria das espécies decíduas das florestas secas na Tailândia e Índia produziu novas folhas entre um e dois meses antes das chuvas de monção, durante o período mais seco e quente do ano, em torno do equinócio de primavera (ELLIOT et al., 2006). Esses autores sugeriram que a produção de nova folhagem um pouco antes da estação chuvosa pode otimizar ganhos em fotoassimilados para árvores em florestas secas com estação favorável ao crescimento de curta duração
A incisão foliar em $D$. cearensis mostrou relação positiva com a precipitação pluviométrica naqueles dois períodos. Essa fenofase, em plantas de florestas tropicais secas, correlacionou-se com ocorrência de chuvas (BULLOCK; SOLÍS-MAGALLANES, 1990) e com a disponibilidade de água no solo (BORCHERT, 1994a, b).

O alto índice de precipitação pluviométrica registrado em 2009 deve ter contribuído para a floração observada em janeiro de 2010, considerada alta se comparada com a de janeiro de 2011, que foi influenciada pelas poucas chuvas ocorridas em 2010. No entanto, a floração e frutificação de algumas espécies arbóreas não seguem um ciclo anual previsível. Há anos em que ocorre elevada produção de sementes viáveis seguidos por anos em que as árvores são estéreis ou produzem quantidade mínima de flores e frutos (KELLY; SORK, 2002; ROCHA et al., 2006). É possível que a floração de algumas espécies esteja mais sob a influência de variáveis bióticas, ocorrendo a sincronização das floradas com as demais espécies da vegetação (ISAGI et al., 1997). De modo semelhante, diferentes indivíduos arbóreos da mesma espécie tendem a sincronizar sua reprodução sem que haja influência de fatores ambientais (SATAKE; IWASA, 2000)

A floração, no entanto, também pode se relacionar com o nível de energia capturado pelas plantas (ISAGI et al., 1997). Esses autores assumiram que determinada árvore ganha um quantum de energia a cada ano e não se reproduzirá enquanto o nível de reserva de energia permanecer abaixo de determinado limite. Uma vez que a reserva de energia excede esse limite, a árvore floresce e pode produzir óvulos para serem fecundados por meio de pólen de outros indivíduos. O investimento realizado em sementes e frutos produzidos a partir desses óvulos esgota a reserva de energia da árvore. Dependendo do grau de depleção de energia, uma única árvore pode mostrar tanto uma reprodução constante ao longo do ano quanto uma reprodução flutuante, descrita por meio de uma série temporal caótica.

A curta longevidade das flores de Dalbergia cearensis é semelhante à das principais espécies de plantas neotropicais. Segundo Primack (1985), o tempo de duração floral seria o resultado de uma demanda conflitante entre a perda de sua capacidade reprodutiva e o custo fisiológico de sua produção e manutenção. Nessas condições, manter flores abertas por tempo maior implicaria maior custo que benefício para a reprodução. 
Apesar da dificuldade em se prever floração e da reserva de energia excedente para o florescimento (ISAGI et al., 1997), em regiões semiáridas, a chuva pode ser fator responsável pelo desencadeamento e espaçamento da floração (REICH; BORCHERT, 1982, 1984). O florescimento de árvores e arbustos, em vegetação tropical semiárida no Nordeste da Venezuela, ocorreu ao final da estação seca, período em que ocorrem poucas chuvas (LAMPE et al., 1992). Essa não é a única estratégia reprodutiva de árvores em florestas secas. Em estudo realizado em Floresta Tropical Seca na Bolívia, Justiniano e Fredericksen (2000) observaram padrão bimodal da floração e frutificação das árvores, com um pico principal no fim da estação seca e um pico menor durante a estação da chuva.

Dalbergia cearensis apresentou pico de floração durante o período chuvoso. No México, em uma floresta decídua a maioria das espécies floresceu no início da estação chuvosa, algumas no fim da estação chuvosa e poucas no período seco (BULLOCK; SOLÍSMAGALLANES, 1990). Em florestas tropicais secas com distribuição bimodal das chuvas é observada a distribuição bimodal da floração, e o tempo de surgimento da floração varia de ano para ano com a sazonalidade da precipitação (BORCHERT et al., 2005).

As sâmaras de D. cearensis, achatadas e indeiscentes, são dispersas o ano inteiro após se desprenderem lentamente das panículas axilares compactas. Dalbergia cearensis mantém seus frutos durante todos os meses do ano, mas os frutos amadurecem apenas no final da estação chuvosa. No entanto, os frutos de D. cearensis permanecem ligados aos ramos das plantas por toda a estação seca, sendo pouco a pouco dispersos. Apesar da diminuição na intensidade de frutificação, frutos remanescentes do primeiro ano se juntaram aos produzidos no segundo, tornando impossível a distinção entre eles. Embora os frutos tenham se desenvolvido durante a estação chuvosa, a dispersão de seus propágulos indeiscentes ocorreu durante a estação seca (julho a dezembro).

No Nordeste da Venezuela, em área de vegetação semiárida, Lampe et al. (1992) registraram a frutificação de árvores e arbustos em todos os meses do ano, porém a maturação dos frutos ocorreu apenas na estação seca e no início das chuvas. A assincronia na dispersão dos frutos entre indivíduos de certas espécies é considerada uma adaptação que resulta na redução de sua predação e, consequentemente, aumenta a probabilidade de sucesso na germinação e no recrutamento (WHEELWRIGHT, 1985).

Os frutos em florestas tropicais sazonais, em sua maioria, amadurecem e são dispersos pelo vento no final da estação seca, quando a maior parte das árvores está sem folhas e os ventos são fortes (RATHCKE; LACEY, 1985). Em florestas estacionais no Panamá, $75 \%$ das espécies lenhosas germinam no início da estação chuvosa. Nessas florestas marcadas pela sazonalidade do clima, a frutificação no início da estação chuvosa favorece a dispersão dos frutos na estação seca e a germinação das sementes e estabelecimento de plântulas no início da estação chuvosa (RATHCKE; LACEY, 1985).

\section{CONCLUSÕES}

A fenologia da espécie Dalbergia cearensis acompanha a sazonalidade das chuvas, com a queda de folhas no início da estação seca e o brotamento nas primeiras chuvas. A floração e frutificação ocorrem no início das chuvas, e os diásporos de D. cearensis são dispersos o ano inteiro após se desprenderem lentamente das panículas axilares compactas.

\section{AGRADECIMENTOS}

Aos proprietários da Reserva Particular do Patrimônio Natural (RPPN) Fazenda Não me Deixes, Senhora Maria Luíza de Queiroz e seus filhos Flávio de Queiroz Salek e Daniel Queiroz Salek, por permitirem a realização desta pesquisa na área da Unidade de Conservação; ao Instituto Brasileiro do Meio Ambiente e dos Recursos Naturais Renováveis - IBAMA, pela liberação, em tempo integral, do primeiro autor para a realização do Doutorado em Ecologia e Recursos Naturais no Departamento de Biologia da Universidade Federal do Ceará; e ao Professor Rogério Parentoni Martins, pela valiosa crítica e pelas sugestões a este trabalho.

\section{REFERÊNCIAS}

BENCKE, C. S. C.; MORELLATO, L. P. C. Comparação de dois métodos de avaliação da fenologia de plantas, sua interpretação e representação. Revista Brasileira de Botânica, v.25, n.3, p.269-275, 2002. 
BORCHERT, R. Soil and stem water storage determine phenology and distribution of tropical dry forest trees. Ecology, v.75, n.5, p.1437-1449, 1994a

BORCHERT, R. Water status and development of tropical trees during seasonal drought. Trees, v.8, n.1, p.115-125, 1994b.

BORCHERT, R. Phenology and flowering periodicity of Neotropical dry forest species: evidence from herbarium collections. Journal of Tropical Ecology, v.12, n.1, p.65-80, 1996.

BORCHERT, R. et al. Photoperiodic induction of synchronous flowering near the Equator. Nature, v.433, p.627-629, 2005.

BORCHERT, R.; RIVERA, G.; HAGNAUER, W. Modification of vegetative phenology in a tropical semi-deciduous forest by abnormal drought and rain. Biotropica, v.34, n.1, p.27-39, 2002.

BULLOCK, S. H.; SOLIS-MAGALLANES, J. A. Phenology of canopy trees of a tropical deciduous forest in México. Biotropica, v.22, n.1, p.22-35, 1990.

CARVALHO, A. M. A synopsis of the genus Dalbergia (Fabaceae, Dalbergieae) in Brazil. Brittonia, v.49, n.1, p.87-109, 1997.

D’ANGIOLELLA, G. L. B.; VASCONCELOS, V. L. D. BHÍDRICO GD 4.0-2004: planilha eletrônica para cálculo do balanço hídrico climatológico normal utilizando diferentes métodos de estimativa da evapotranspiração potencial. Revista Brasileira de Agrometeorologia, v.11, n.2, p.375-378, 2003.

D’ANGIOLELLA, G. L. B.; VASCONCELOS, V. L. D. BHÍDRICO GD 4.0-2004: planilha eletrônica para cálculo do balanço hídrico climático. Revista Bahia Agrícola, v.6, n.3, p.14-16, 2004.

ELLIOT, S.; BAKER, P. J.; BORCHERT, R. Leaf flushing during the dry season: the paradox of Asian monsoon forests. Global Ecology and Biogeography, v.15, n.3, p.248-257, 2006.

\section{EMPRESA BRASILEIRA DE PESQUISA}

AGROPECUÁRIA- EMBRAPA. Centro Nacional de Pesquisa de Agroindústria Tropical. Ministério da Agricultura, Pecuária e Abastecimento. Dados climatológicos: Estação de Quixadá, 2003. Fortaleza: 2004. (Documentos, 88).
FOURNIER, L. A. Um método cuantitativo para la medición de características fenológicas en arboles. Turrialba, v.24, n.4, p.422-423, 1974.

FOURNIER, L. A.; CHARPANTIER, C. El tamaño de la muestra y la frecuencia de lãs observaciones en el estudio de las características fenológicas de las árboles tropicales. Turrialba, v.25, n.1, p.45-48, 1975.

GRIZ, L. M. S.; MACHADO, I. C. S. Fruiting phenology and seed dispersal syndromes in caatinga, a tropical dry forest in the northeast of Brazil. Journal of Tropical Ecology, v.17, n.2, p.303-321, 2001.

HOLBROOK, N. M.; WHITBECK, J. L.; MOONEY, H. A. Drought responses of Neotropical dry forest trees. In: BULLOCK, S. H.; MOONEY, H. A.; MEDINA, E. (Ed.) Seasonally dry tropical forests. Cambridge: Cambridge University Press, 1995. p.243-276.

ISAGI, K. et al. How does masting happen and synchronize? Journal of Theoretical Biology, v.187, n.2, p.231-239, 1997.

JARAMILLO, V. J.; SANFORD Jr., R. L. Nutrient cycling in tropical deciduous forests. In: BULLOCK, S. H.; MOONEY, H. A.; MEDINA, E. (Org.) Seasonally dry tropical forests. New York, Cambridge, 1995.p.346-361.

JOLLY, W. M.; RUNNING, S. W. Effects of precipitation and soil water potential on drought deciduous phenology in the Kalahari. Global Change Biology, v.10, n.3, p.303-308, 2004.

JUSTINIANO, M. J.; FREDERICKSEN, T. S. Phenology of tree species in Bolivian dry forests. Biotropica, v.32, n.2, p.276-281, 2000.

KELLY, D.; SORK, V. L. Mast seeding in perennial plants: why, how, where? Annual Review of Ecology and Systematics,v. 33, p.427-447, 2002.

KÖPPEN, W. Climatologia: com um estúdio de los climas de La tierra. Mexico: Fondo de Cultura Economica, 1948.478p.

LAMPE, M. G. et al. Seasonal flowering and fruiting patterns in tropical semi-arid vegetation of northeastern Venezuela. Biotropica, v.24, n.1, p.64-76, 1992. 
LIMA, A. L. A.; RODAL, M. J. N. Phenology and wood density of plants growing in the semi-arid region of northeastern Brazil. Journal of Arid Environments, v.74, n.11, p.1363-1373, 2010.

LORENZI, H. Árvores brasileiras: manual de identificação e cultivo de plantas arbóreas nativas do Brasil. Nova Odessa: Instituto Plantarum, 2009. v.3

MACHADO, I. C. S.; BARROS, L. M.; SAMPAIO, E. V. S. B. Phenology of Caatinga Species at Serra Talhada, PE, Northeastern Brazil. Biotropica, v.29, n.1, p.57-68, 1997.

NIMER, E. Climatologia do Brasil. 2.ed. Rio de Janeiro: IBGE-SUPREN, 1989. (Fundação IBGE-SUPREN, Recursos Naturais e Meio Ambiente).

NOGUEIRA, F. C. B.; MEDEIROS FILHO, S.; GALLÃO, M. I. Caracterização da germinação e morfologia de frutos, sementes e plântulas de Dalbergia cearensis Ducke (pau-violeta)-

Fabaceae. Acta Botanica Brasilica, v.24, n.4, p.978-985, 2010.

PAVÓN, N. P.; BRIONES, O. Phenological patterns of nine perennial plants in an intertropical semiarid Mexican scrub. Journal of Arid Environments, v.49, n.2, p.265-277, 2001.

PRIMACK, R. B.; HALL, P. Biodiversity and forest change in Malaysian Borneo. Bioscience, v.42, n.11, p.829-837, 1992

RATHCKE, B.; LACEY, E. P. Phenological patterns of terrestrial plants. Annual Review of Ecology and Systematics, v.16, p.179-214, 1985.

REICH, P. B.; BORCHERT, R. Phenology and ecophysiology of the tropical tree, Tabebuia neochrysantha (Bignoniaceae).Ecology, v.63, n.2, p.294-299, 1982.

REICH, P. B.; BORCHERT, R. Water stress and tree phenology in a tropical dry forest in the lowlands of Costa Rica. Journal of Ecology, v.72, n.1, p.61-74, 1984

RIZZINI, C. T. Árvores e madeiras úteis do Brasil - manual de dendrologia brasileira. 2.ed. Porto Alegre: Edgard Blucher, 1978.

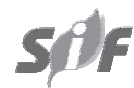

ROCHA, O. J.; VÍLCHEZ, B.; ANCHETTA, A. L. A. A mast fruiting episode of the tropical tree Peltogyne purpurea (Caesalpinaceae) in the Osa Peninsula, Costa Rica. Revista de Biología Tropical, v.54, n.4, p.1151-1155, 2006.

SAMPAIO, E. V. S. B. Overview of the Brazilian Caatinga. In: BULLOCK, S. H. MOONEY, H. A.; MEDINA, E. Seasonally dry tropical forests. Cambridge: University Press, 1995. p.35-63.

SATAKE, A.; IWASA, Y. Pollen coupling of forest trees: forming synchronized and periodic reproduction out of chaos. Journal of Theoretical Biology, v.203, n.1, p.63-84, 2000.

SILVERTOWN, J. W. The evolutionary ecology of mast seeding in trees. Biological Journal of the Linnean Society, v.14, n.2, p.235-250, 1980.

SINGH, K. P.; KUSHWAHA, C. P. Emerging paradigms of tree phenology in dry tropics. Current Science, v.89, n.6, p.964-975, 2005.

STATISTICAL PACKAGE FOR THE SOCIAL SCIENCES - SPSS. Chicago: Statistical Product and Service Solutions, 2007.

WHEELWRIGHT, N.T. Competition for dispersers, and the timing of flowering and fruting in a guild of tropical trees. Oikos, v.44, n.3, p.465-477, 1985.

YADAV, R. K.; YADAV, A. S. Phenology of selected woody species in a tropical dry deciduous forest in Rajasthan, India. Tropical Ecology, v.49, n.1, p.25-34, 2008.

ZAGT, R. J. Pre-dispersal and early postdispersal demography, and reproductive litter production in the tropical tree Dicymbe altsonii in Guyana. Journal of Tropical Ecology, v.13, n.4, p.511-526, 1997.

ZAR, J. H. Biostatistical analysis. 3.ed. New Jersey: Prentice-Hall, 1996. 662p.

Revista Árvore, Viçosa-MG, v.37, n.4, p.657-667, 2013 
